\title{
Dogs avoid people who behave negatively to their owner: third- party affective evaluation
}

$\operatorname{AUTHOR}(\mathrm{S}):$

Chijiiwa, Hitomi; Kuroshima, Hika; Hori, Yusuke; Anderson, James R.; Fujita, Kazuo

\section{CITATION:}

Chijiiwa, Hitomi ...[et al]. Dogs avoid people who behave negatively to their owner: thirdparty affective evaluation. Animal Behaviour 2015, 106: 123-127

\section{ISSUE DATE:}

2015-06-18

URL:

http://hdl.handle.net/2433/198493

\section{RIGHT:}

(c) 2015 Elsevier. Licensed under the Creative Commons Attribution-NonCommercial-No Derivatives 4.0 International http://creativecommons.org/licenses/by-nc-nd/4.0/. NOTICE: this is the author's version of a work that was accepted for publication in Animal Behaviour. Changes resulting from the publishing process, such as peer review, editing, corrections, structural formatting, and other quality control mechanisms may not be reflected in this document.

Changes may have been made to this work since it was submitted for publication. A definitive version was subsequently published in Animal Behaviour Volume 106, Pages 123-127, doi:10.1016/j.anbehav.2015.05.018; ; 許諾条件により本文フ アイルは2017-06-18に公開;; This is not the published version. Please cite only the published version.; この論文は出版社 版でありません。引用の際には出版社版をご確認ご利用ください。 
1 Dogs avoid people who behave negatively to their owner: third-party affective evaluation

2

3 Hitomi CHIJIIWA ${ }^{\mathrm{a}}$, Hika KUROSHIMA ${ }^{\mathrm{a}}$, Yusuke HORI ${ }^{\mathrm{a}, \mathrm{b}}$, James R. ANDERSON ${ }^{\mathrm{a}}$,

4 Kazuo FUJITA ${ }^{\mathrm{a}, *}$

$5 \quad$ aagraduate School of Letters, Kyoto University, Kyoto, Japan

6 bJapan Society for the Promotion of Science, Tokyo, Japan

7

8 *Correspondence: K. Fujita, Department of Psychology, Graduate School of Letters,

9 Kyoto University, Yoshida-honmachi, Sakyo, Kyoto 606-8501, Japan.

10 E-mail address: kfujita@bun.kyoto-u.ac.jp (K. Fujita). 


\section{ABSTRACT}

Social eavesdropping, or social evaluation of third-party interactions, is a first step to image scoring, which is a key feature of humans' large-scale cooperative society. Here we asked whether domestic dogs evaluate humans interacting with one another over neutral objects. In two experimental conditions, the dog's owner tried to open a container to get a junk object that was inside, then requested help from an actor sitting next to her/him, while the dog watched the interaction. In the Helper condition, the actor held the container stable to help the owner to open it. In the Nonhelper condition, the actor turned away and refused to help. In the Control condition, the actor simply turned away in the absence of any request for help. A neutral person sat at the other side of the owner throughout these interactions. After the interaction the actor and the neutral person each offered a piece of food to the dog. Dogs chose food randomly in the Helper and the Control conditions, but were biased against the actor in the Nonhelper condition. The dogs' avoidance of someone who behaved negatively to the owner suggests that social eavesdropping may be shared with a nonprimate species.

\section{KEYWORDS}

dogs, image scoring, social eavesdropping, third-party evaluation, social evaluation, social preference, cooperation, negativity bias, helping, moral judgment 
Humans form large-scale cooperative societies, in which members often help one another for no apparent benefits to themselves. Indirect reciprocity has been proposed as an important factor maintaining this phenomenon (e.g. Melis \& Semmann, 2010; Nowak \& Sigmund, 2005). For this mechanism to work, members must be sensitive to third-party interactions. Such sensitivity is often referred to as social eavesdropping. It involves an affective evaluation of third-party interactions, and it appears to develop early in human infants. For instance, Hamlin, Wynn, and Bloom (2007) exposed infants as young as 6 months old to an animation, in which one simple-shaped character helped another to climb up a hill whereas another blocked the attempt. When the infants were asked to choose between the characters, they chose the nasty character less frequently than the helpful character. The same authors found this to be true even for 3-month-olds (Hamlin \& Wynn, 2011; Hamlin, Wynn, \& Bloom, 2010). Such evaluation later converts into differentiated helping behaviour; Vaish, Carpenter, and Tomasello (2010) demonstrated that 3-year-old children were less willing to give a ball to an actor who behaved harmfully to another than to a harmless person.

This sensitivity has been tested in a few nonhuman species including chimpanzees, Pan troglodytes (Subiaul, Vonk, Okamoto-Barth, \& Barth, 2008), tufted capuchin monkeys,

Cebus apella (Anderson, Kuroshima, Takimoto, \& Fujita, 2013; Anderson, Takimoto, 
48 Kuroshima, \& Fujita, 2013), common marmosets, Callithrix jacchus (Kawai, Yasue,

49 Banno, \& Ichinohe, 2014), domestic dogs, Canis familiaris (Freidin, Putrino, D’Orazio,

50 \& Bentosela, 2013; Kundey, De Los Reyes, Royer, Molina, Monnier, German, \& Coshun,

2011; Marshall-Pescini, Passalacqua, Ferrario, Valsecchi, Prato-Previde, 2011;

Nitzschner, Kaminski, Melis, \& Tomasello 2014; Nitzschner, Melis, Kaminski, \& Tomasello, 2012), and Labroides dimidiatus cleaner fish (Bshary \& Grutter, 2006). In

most of these studies the participants watched third-party interactions, usually exchanges, involving food, which raises the possibility that participants simply preferred actors who were more likely to give them a better chance of getting food. Two studies by Anderson et al. (2013a, b) were more persuasive, as in those studies actors handled toys that were of no apparent value to capuchin monkeys.

Whereas dogs are highly sensitive to human actions directed to themselves, whether they are sensitive to third-party interactions among others has been under debate. Kundey et al. (2011) showed that dogs preferred an actor who generously gave food to a begging person over another who withheld it. But in that study the dogs also preferred an actor who 'gave' food to a box rather than the beggar. Marshall-Pescini et al. (2011) reported that dogs showed no preference when there was no beggar, thus demonstrating that some interaction between the actor and the beggar was critical for the dogs' social preference. 
By contrast, Nitzschner et al. (2012) argued that dogs evaluate only direct experiences; showed no preference after watching actors behaving in these ways towards another dog.

Evidence for such second-party evaluation was also obtained by Petter, Musolino, Roberts, and Cole (2009), who showed that dogs preferred a cooperative human to a deceiving human in an object choice task. Recently, Nitzschner et al. (2014) reported that dogs preferred the location, not the person, where a beggar received food. Thus, evidence for third-party social evaluations by dogs is weak.

Here we used a newly devised procedure to test whether dogs could evaluate actors who interacted with their owners either cooperatively or noncooperatively. To exclude the possibility of a preference due to association between one of the actors and attractive objects such as food, the actors never touched the object involved in the interaction; that is, the object stayed with the owner.

\section{METHODS}

Participants

83 failed to complete the test trials due to weak motivation $(N=16)$ or experimenter error 
84 violating prescheduled test conditions and/or wrong acting $(N=10)$. Dogs were considered to be insufficiently motivated if they failed to approach the actor or the neutral person within $30 \mathrm{~s}$ in three repeated trials. In this case no further tests were given. Only one dog in the Control group (see below) was excluded after watching the recorded video due to failure to attend to the acting. The dogs were randomly divided into three groups of 18

89 (nine males, nine females), and each participated in one of two experimental conditions

90 called Helper and Nonhelper conditions, or a Control condition. The dogs were of various

91 breeds, and ranged in age from 7 months to 14 years, with the average age for the Helper,

92 Nonhelper and Control groups being 4.54, 5.02 and 5.67 years, respectively (see 93 Appendix Table A1).

94 Ethical Note

The experiment was approved by the Animal Experiments Committee of the Graduate

School of Letters, Kyoto University. The owners signed a written informed consent before their dogs were tested.

Apparatus and Procedure

Trials started with the owner in possession of a transparent cylindrical container (13 cm in diameter and $12.5 \mathrm{~cm}$ high), with a lid, in which there was an object (roll of vinyl tape, diameter $5.5 \mathrm{~cm}$ ). The actor sat to one side of the owner, and a neutral person sat to 
102 the other side. The dog was lightly restrained by an experimenter ca. $1 \mathrm{~m}$ from the owner 103 (Fig. 1).

104 Upon a vocal cue from another experimenter, the owner started trying to open the lid 105 of the container. For the two experimental groups, after 8-10 s of failed attempts, the 106 owner requested help by turning towards and holding the container towards the actor. In 107 the Helper condition, the actor responded by holding the bottom of the container. With 108 this help, the owner successfully opened the lid, removed the object, showed it to the dog, 109 then placed it back into the container and put the lid firmly back on. This final action 110 ensured the same end state of the interaction as in the Nonhelper condition. In the

111 Nonhelper condition, in response to the owner's request the actor showed unwillingness

112 to help by turning away for 1-2 s. The owner continued trying to open the container, in

113 vain. In the Control condition, after 8-10 s of attempting to open the lid the owner stopped

114 and simply looked down at the container for 1-2 s while the actor turned away; critically,

115 there was no request for help by the owner. The owner resumed trying, in vain.

116 All conditions ended with the owner placing the container in front of her/him. The entire demonstration lasted 15-20 s. Immediately thereafter, the actor and the neutral

118 person extended both arms at the same time, offering a piece of the dog's favourite food 119 on their palms. The dog was allowed to pick one reward. 
120 To exclude any inadvertent cueing, neither the actor nor the neutral person looked at

121 the dog during the demonstration. During the choice phase, they looked down at the floor

122 and the owner's eyes were closed. The owner was ignorant of the purpose of the

123 experiment. These careful procedures were followed because some dogs can be trained

124 to use even momentary eye gaze to detect a cued container in an object choice task

125 (Miklósi, Polgárdi, Topál, \& Csányi, 1998). The dog’s choice was defined as the first

126 person the dog sniffed, licked or took the food from. This behaviour was obvious; post

127 hoc video analyses of $20 \%$ of the dogs' choices completely matched the on-site decision.

128 Each dog received four trials in which the identities of the actor and neutral person

129 were unchanged. The identity was different across participant dogs but both were females

130 unfamiliar to the dog. The left-right positions of actors were counterbalanced across trials

131 and on the first trial across individuals.

132

RESULTS

134 Figure 2 shows the number of times the actor was chosen in each condition. Whereas this frequency was at chance in Control (Wilcoxon signed-rank test: $V=9.50, P=0.488$, $r=0.16)$ and Helper conditions $(V=48.00, P=0.177, r=0.32)$, it was significantly 
1380.023 , 95\% confidence interval $0.50-1.00, r=0.54)$. The difference in frequency of

139 choosing the actor in the three conditions was significant, and the effect size $\left(\eta^{2}\right)$ was

140 satisfactory (Kruskal-Wallis test: $\chi_{2}^{2}=8.18, P=0.017, \eta^{2}=0.15$ ). Post hoc multiple

141 comparisons using Mann-Whitney $U$ tests with Bonferroni correction (corrected alpha =

142 0.017) revealed a significant difference between Nonhelper and Helper conditions with a

143 satisfactory effect size $\left(U=244.50, N_{1}=N_{2}=18, P=0.006\right.$; $95 \%$ confidence interval

$1440.00-2.00, r=0.46)$. There was no difference between Helper and Control conditions ( $U$

$\left.145=127.00, N_{1}=N_{2}=18, P=0.241, r=0.20\right)$. Unfortunately, the difference between

146 Nonhelper and Control conditions was not significant, either $\left(U=215.00, N_{1}=N_{2}=18\right.$,

$147 P=0.075, r=0.30$ ), because of one exceptional dog in the Nonhelper condition choosing

148 the actor in all four trials (note that all other dogs in this condition chose the actor in two

149 or fewer trials; see Appendix Table A2). However, a Fisher exact test of the number of

150 dogs choosing the actor in different numbers of trials (see Appendix Table A2) revealed

151 a significant difference between Nonhelper and Control conditions ( $P=0.016)$.

152 There was also no significant correlation between dogs' age and choice of the actor

153 (Spearman rank correlation: $r_{\mathrm{S}}=-0.35, P=0.161, r_{S}=0.40, P=0.122$ and $r_{S}=-0.33, P$

$154=0.185$, respectively, for the Helper, Nonhelper and Control conditions. 
DISCUSSION

157 The present results clearly show that after witnessing an actor behaving

158 noncooperatively towards their owners, dogs avoided that actor, despite no explicit reason

159 to do so in terms of likelihood of obtaining food. In contrast, dogs showed no clear

160 preference for an actor who cooperated by helping their owners. This asymmetrical

161 preference is reminiscent of that shown by 3- and 5-month-old infants in Hamlin et al.'s

162 (2007; 2010) studies, 3-year-old children in Vaish et al.’s (2010) study and tufted capuchin

163 monkeys in Anderson et al.'s (2013a, b) studies. It is noteworthy that in all of these studies,

164 including the present one, interactions involved items that were of no direct interest to the

165 participants. In fact no dog tried to get the item out of the container before or after

166 choosing a person.

167 Might the turning away gesture in the Nonhelper condition somehow have caused the dogs to avoid the actor? The result for the Control condition makes this unlikely; dogs did not discriminate between the actor who spontaneously turned away and the neutral person. Therefore, explicit refusal to respond positively to the owner's request for help emerges as the most likely reason for the dogs’ avoidance of that actor. actor, could be the cue for the dogs' evaluation. However, this is also unlikely because the 
174 dogs' differential choice was between two conditions in which the owner showed the same expressions resulting from the failure to open the container. In contrast, there was

176 no difference in the dogs' choice between the Helper condition, the only condition in

177 which the owner showed happiness, and the other (unhappy) conditions.

178 This ability for social eavesdropping might be expected to improve with age or amount

179 of social experience with humans. However, we found no significant correlation between

180 age and the dogs' choices. But whether dogs, like humans, engage in this type of social

181 evaluation ability from an early age awaits additional work. Additionally, further work

182 could address the issue of whether dogs, like young human infants (Johnson, Slaughter,

183 \& Carey, 1998), are more likely to respond in social ways to agents that are perceived as

184 'social' rather than 'nonsocial.'

185 It is important to note that in this study dogs chose between two persons, neither of

186 whom was explicitly associated with the item (a roll of vinyl tape) targeted in the

187 interaction; the nonhelpful actor simply ignored the apparatus and the helpful actor simply

188 held the container. In previous studies claiming dogs' sensitivity to third-party

189 interactions (Kundey et al., 2011; Marshall-Pescini et al., 2011), dogs might have

190 approached the person or place that was associated with food. In fact Nitzschner et al.,

191 (2012, 2014) suggested that multiple cues might influence dogs' choices, such as where 
192 donors stood and several features of the beggar's behaviour. Thus, the present results

193 provide much stronger evidence for social eavesdropping by dogs.

194 Importantly, we have found this ability in a highly social, noncooperatively breeding species, which challenges a recent suggestion that sensitivity to unfair reciprocity in third-

196 party social exchanges may require cooperative and prosocial tendencies of species, as

197 shown in cooperative breeders such as marmosets (Kawai, et al., 2014). The present

198 demonstration suggests that highly developed social competence rather than cooperative

199 tendencies underlies these affective social evaluations.

200 Conceivably, this demonstration of social eavesdropping by dogs was facilitated by the

201 owner's involvement in the interaction. Attachments between dogs and their owners can

202 be strong, and the former may be particularly sensitive to how other people treat the latter.

203 Future work should include varying the identities of the people involved, as well as assessing whether dogs also evaluate other dogs' third-party interactions. The last point seems important for knowing the effects of domestication history; if dogs show a similar sensitivity, then domestication enhanced their general social sensitivity, and if not, its effects are object-specific. 
210 cooperative societies. An intriguing case in this context is the cleaner fish tested by

211 Bshary and Grutter (2006). Bystanders of this species prefer staying near cooperative

212 cleaners than cheaters that remove mucus rather than ectoparasites from the client.

213 Although they apparently do this for their own benefit, this fish study underlines the

214 advantage of testing social eavesdropping in various species of different taxa to better

215 understand the evolutionary history of such social sensitivity.

216 Finally, a plausible account must address whether and how this social eavesdropping

217 ability translates into reputation formation. A logical next step is to ask whether

218 eavesdroppers take the presence of others into account to adjust their own behaviour.

219 Initial work suggests that, unlike human children, chimpanzees do not attempt to 'manage'

220 their reputations (Engelmann, Herrmann, \& Tomasello, 2012), but a clearer picture must

221 await further studies using alternative procedures, as well as assessing social

222 eavesdropping abilities in other highly social animals, for example dolphins, elephants

223 and corvids.

\section{ACKNOWLEDGMENTS}

226 This study was financially supported by the JSPS Grant-in-Aide for Scientific Research

227 (A) No. 25240020 to K.F. and that for Priority Areas No. 25118002. We thank Aya 
228 Norikiyo and Saki Saito for their assistance in conducting experiments and Eriko Ogura

229 for her help in recruiting participants. We also thank all dogs and dog owners for their

230 cooperation. We declare that we have no conflicts of interest with respect to the authorship

231 or the publication of this article.

232

233

\section{REFERENCES}

234 Anderson, J. R., Kuroshima, H., Takimoto, A., \& Fujita, K. (2013a). Third-party social evaluation of humans by monkeys. Nature Communications, 4, 1561 (doi: 10.1038/ncomms2495)

Anderson, J. R., Takimoto, A., Kuroshima, H., \& Fujita, K. (2013b). Capuchin monkeys judge third-party reciprocity. 10.1016/j.cognition.2012.12.007)

Engelmann, J. M., Herrmann, E., \& Tomasello, M. (2012). Five-year olds, but not chimpanzees, attempt to manage their reputations. PLoS One 7(10), e48433. (doi:10.1371/journal.pone.0048433)

243 Bshary, R., \& Grutter, A. S. (2006). Image scoring and cooperation in a cleaner fish mutualism. Nature, 441, 975-978. (doi:10.1038/nature04755)

245 Freidin, E., Putrino, N., D’Orazio, M., \& Bentosela, M. (2013). Dogs’ eavesdropping 
from people’s reactions in third party interactions. PLoS One, 8(11), e79198. (doi:

Hamlin, J. K., \& Wynn, K. (2011) Young infants prefer prosocial to antisocial others.

Hamlin, J. K., Wynn,K., \& Bloom, P. (2007) Social evaluation by preverbal infants.

Hamlin, J. K., Wynn, K., \& Bloom, P. (2010). Three-month-olds show a negativity bias in their social evaluations. Developmental Science, 13(6), 923-929. (DOI: 10.1111/j.1467-7687.2010.00951.x)

Johnson, S., Slaughter, V. \& Carey, S. (1998). Whose gaze will infants follow? The elicitation of gaze-following in 12-month-olds. Developmental Science, 1(2), 233238.

Kawai, N., Yasue, M., Banno, T., \& Ichinohe, N. (2014) Marmoset monkeys evaluate third-party reciprocity. Biology Letters, 10, 20140058. (http://dx.doi.org/10.1098/rsbl.2014.0058)

Kundey, S., De Los Reyes, A., Royer, E., Molina, S., Monnier, B., German, R., \& Coshun, 
264 Marshall-Pescini, S., Passalacqua, C., Ferrario, A., Valsecchi, P., \& Prato-Previde, E. (2011). Social eavesdropping in the domestic dog. Animal Behaviour, 81, 1177-1183. (doi: :10.1016/j.anbehav.2011.02.029)

Melis, A. P., \& Semmann, D. (2010). How is human cooperation different? Philosophical Transactions of the Royal Society B, 365, 2663-2674. (doi: 10.1098/rstb.2010.0157 )

Miklósi, Á., Polgárdi, R., Topál, J. \& Csányi, V. (1998). Use of experimenter-given cues in dogs. Animal Cognition, 1, 113-121.

Nitzschner, M., Kaminski, J., Melis, A., \& Tomasello, M. (2014). Side matters: potential mechanisms underlying dogs' performance in a social eavesdropping paradigm. Animal Behaviour, 90, 263-271 (doi: 10.1016/j.anbehav.2014.01.035)

Nitzschner, M., Melis, A. P., Kaminski, J., \& Tomasello, M. (2012). Dogs (Canis familiaris) evaluate humans on the basis of direct experiences only. PLoS One, 7(10), e46880. (doi:10.1371/journal.pone.0046880)

Nowak, M. A., \& Sigmund, K. (2005). Evolution of indirect reciprocity. Nature, 437, 1291-1298. (doi: 10.1038/nature04131)

Petter, M., Musolino, E., Roberts, W. A., \& Cole, M. (2009). Can dogs (Canis familiaris) 10.1016/j.beproc.2009.07.002) 
282 Subiaul, F., Vonk, J., Okamoto-Barth, S., \& Barth, J. (2008). Do chimpanzees learn

283 reputation by observation? Evidence from direct and indirect experience with

284 generous and selfish strangers. Animal Cognition, 11, 611-623. (doi:

285 10.1007/s10071-008-0151-6)

286 Vaish, A., Carpenter, M., \& Tomasello, M. (2010). Young children selectively avoid helping people with harmful intentions. Child Development, 81, 1661-1669.

288

289 


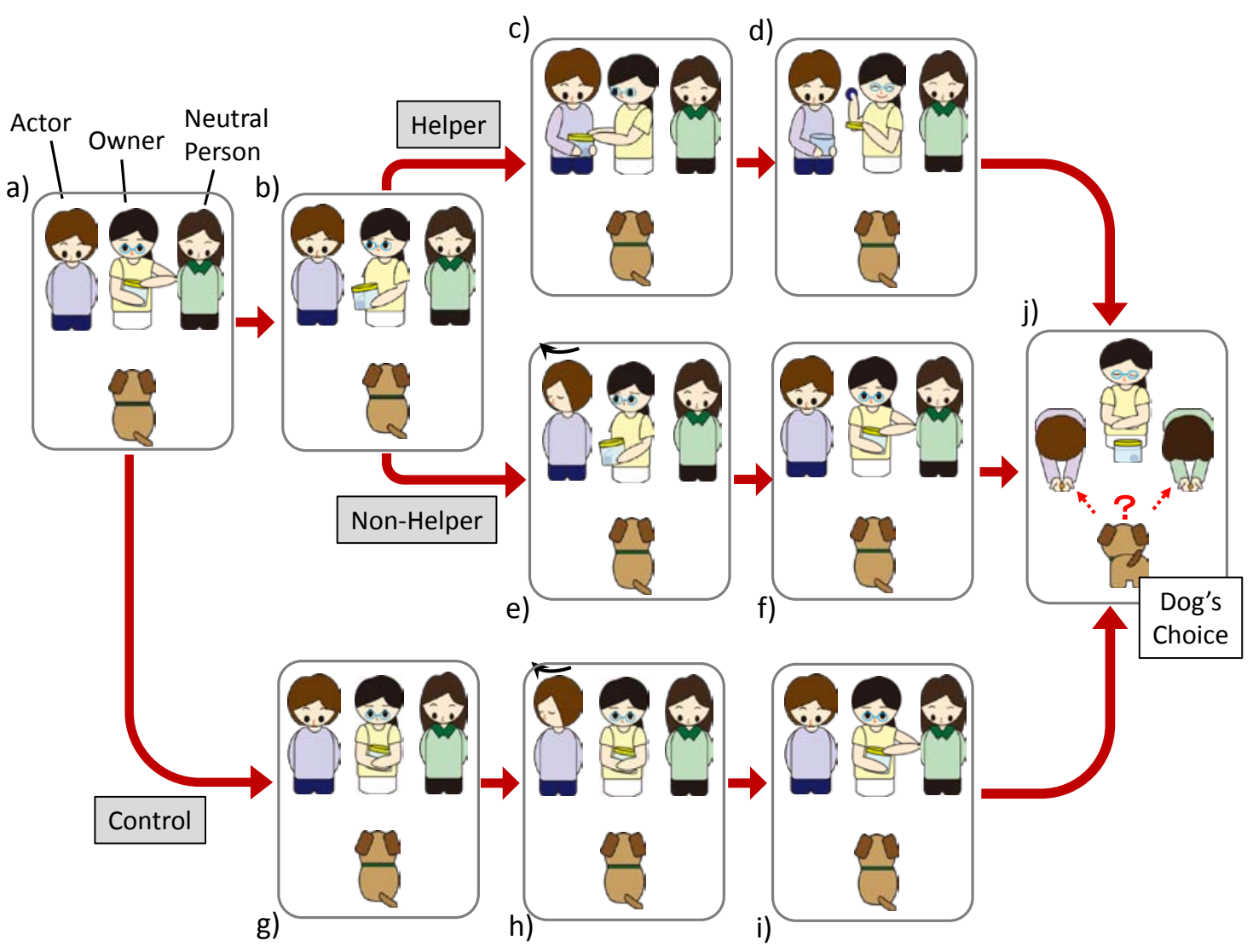

294 Figure 1. A schematic of the experimental procedure. (a) The owner tries to open a container to get a junk object that is inside. (b) In Helper and Nonhelper conditions, the owner requests help from the actor. (c) In the Helper condition (top row), the actor helps the owner, and (d) the owner successfully opens the container and shows the object to the dog. (e) In the Nonhelper condition (middle row), the actor turns away to show unwillingness to help, and (f) the owner continues trying to open the container, in vain.

300 (g) In the Control condition (bottom row), the owner stops trying for a few seconds. (h)

301 The actor turns away. (i) The owner resumes trying to open the container, in vain. (j) In 302 all conditions, the dog finally chooses to take food from the actor or the neutral person. 


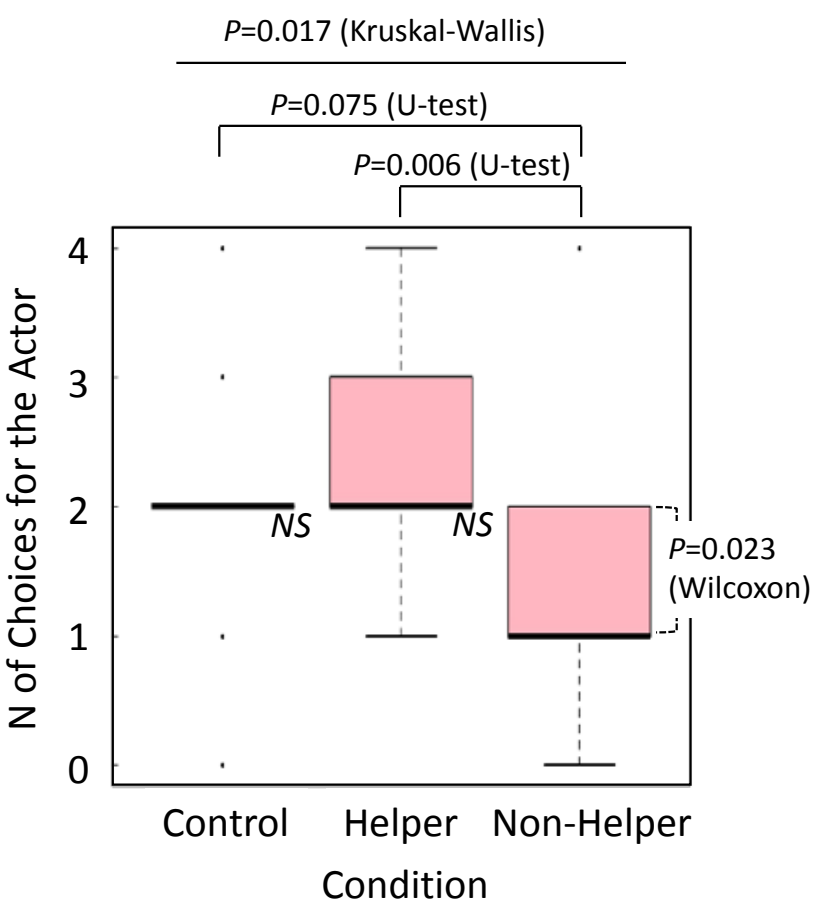

305 Figure 2. A box plot of the number of choices for the actor instead of the neutral person 306 in each condition. The plot shows medians, first and third percentiles, ranges and 307 outliers (dots). 
308

309

310

311

312

313

314

315

316

317

318

319

320

321

322

323

324

325

326

327

328

329

330

331

332

333

334

335

336

337

338

339

340

341

342

343

344

345

346

347

348

349

350

351

352

353

354

\section{Appendix}

Table A1: Participant dogs and choice for the actor in each of the four trials

Trial

Breed

Sex Age $1 \quad 2 \quad 3 \quad 4$ Total (year:month)

\section{Helper condition}

Bichon frise

$\begin{array}{lllllll}\text { F } & 2: 09 & 1 & 1 & 0 & 1 & 3\end{array}$

Cavalier King Charles spaniel

Chihuahua

French bulldog

Golden retriever

\begin{tabular}{|c|c|}
\hline & 8:08 \\
\hline
\end{tabular}

$\begin{array}{lllllll}\text { M } & 2: 05 & 1 & 1 & 1 & 1 & 4\end{array}$

$\begin{array}{lllllll}\text { M } & 7: 05 & 1 & 1 & 1 & 0 & 3\end{array}$

Labrador retriever

$\begin{array}{lllllll}\text { M } & 2: 09 & 1 & 0 & 1 & 0 & 2\end{array}$

Labrador retriever

$\begin{array}{lllllll}\mathrm{F} & 2: 04 & 0 & 1 & 0 & 1 & 2\end{array}$

F $3: 11 \quad 0 \quad 0011001$

Labrador retriever

$\begin{array}{lllllll}\text { M } & 0: 08 & 0 & 0 & 1 & 1 & 2\end{array}$

Miniature schnauzer

$\begin{array}{lllllll}\mathrm{F} & 0: 07 & 1 & 1 & 0 & 1 & 3\end{array}$

Miniature schnauzer

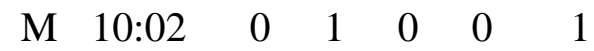

Mongrel

Papillon

Rough collie

Shiba

$\begin{array}{lllllll}\mathrm{F} & 9: 08 & 0 & 0 & 1 & 0 & 1\end{array}$

$\begin{array}{lllllll}\text { M } & 4: 09 & 1 & 1 & 1 & 0 & 3\end{array}$

$\begin{array}{lllllll}\text { F } & 2: 05 & 1 & 1 & 1 & 1 & 4\end{array}$

Toy poodle

$\begin{array}{lllllll}\mathrm{F} & 6: 00 & 0 & 0 & 1 & 0 & 1\end{array}$

\section{Toy poodle}

$\begin{array}{lllllll}\mathrm{F} & 4: 08 & 0 & 1 & 0 & 1 & 2\end{array}$

Yorkshire terrier

$\begin{array}{lllllll}\text { M } & 4: 05 & 1 & 0 & 1 & 0 & 2\end{array}$

Yorkshire terrier

$\begin{array}{lllllll}\text { M } & 3: 10 & 0 & 1 & 0 & 1 & 2\end{array}$

$\begin{array}{lllllll}\text { M } & 4: 03 & 0 & 1 & 0 & 1 & 2\end{array}$

Average/total/median

4.54

\section{Nonhelper condition}

Australian labradoodle

$\begin{array}{crrrrrr}\mathrm{F} & 2: 07 & 1 & 0 & 0 & 1 & 2 \\ \mathrm{M} & 4: 06 & 1 & 1 & 0 & 0 & 2 \\ \mathrm{~F} & 2: 03 & 1 & 0 & 0 & 0 & 1 \\ \mathrm{M} & 3: 11 & 0 & 1 & 0 & 0 & 1 \\ \mathrm{M} & 14: 05 & 1 & 0 & 1 & 0 & 2 \\ \mathrm{~F} & 1: 09 & 0 & 0 & 0 & 0 & 0 \\ \mathrm{M} & 2: 02 & 0 & 0 & 0 & 1 & 1 \\ \mathrm{~F} & 6: 06 & 0 & 1 & 0 & 1 & 2 \\ \mathrm{M} & 7: 10 & 0 & 0 & 1 & 0 & 1 \\ \mathrm{~F} & 4: 10 & 1 & 1 & 1 & 1 & 4 \\ \mathrm{M} & 2: 03 & 0 & 0 & 0 & 1 & 1 \\ \mathrm{~F} & 2: 07 & 0 & 0 & 1 & 0 & 1 \\ \mathrm{~F} & 9: 04 & 1 & 0 & 1 & 0 & 2\end{array}$




\begin{tabular}{|c|c|c|c|c|c|c|}
\hline Toy poodle & $\mathrm{M}$ & $2: 00$ & 1 & 0 & 0 & 0 \\
\hline Toy poodle & M & $6: 04$ & 0 & 1 & 0 & 0 \\
\hline Toy poodle & M & $10: 03$ & 0 & 0 & 0 & 0 \\
\hline Welsh corgi Pembroke & $\mathrm{F}$ & 2:08 & 0 & 0 & 1 & 0 \\
\hline Yorkshire terrier & $\mathrm{F}$ & 4:03 & 0 & 1 & 0 & 1 \\
\hline Average/total/median & & 5.02 & 7 & 6 & 6 & 6 \\
\hline
\end{tabular}

\section{Control condition}

365

Australian labradoodle

$\begin{array}{lllllll}\text { F } & 2: 05 & 1 & 1 & 0 & 1 & 3\end{array}$

Bernese mountain dog

$\begin{array}{lllllll}\text { F } & 3: 07 & 0 & 1 & 1 & 0 & 2\end{array}$

368

Chihuahua

$\begin{array}{lllllll}\text { M } & 3: 06 & 1 & 0 & 1 & 0 & 2\end{array}$

369

Chihuahua

$\begin{array}{lllllll}\text { M } & 3: 09 & 1 & 0 & 0 & 1 & 2\end{array}$

370

Chihuahua

$\begin{array}{lllllll}\text { M } & 7: 05 & 0 & 1 & 0 & 1 & 2\end{array}$

371 Chihuahua

F $10: 06 \quad 1 \quad 1 \quad 001103$

372 Chihuahua

373 Golden retriever

$374 \quad$ Irish setter

375 Miniature schnauzer

376 Miniature schnauzer

$\begin{array}{lllllll}\text { F } & 14: 03 & 0 & 1 & 0 & 1 & 2\end{array}$

377 Mongrel

378 Mongrel

379 Pomeranian

$\begin{array}{lllllll}\mathrm{F} & 4: 06 & 0 & 0 & 1 & 1 & 2\end{array}$

380 Pomeranian

$\begin{array}{lllllll}\text { M } & 1: 04 & 0 & 1 & 0 & 1 & 2\end{array}$

$\begin{array}{lllllll}\text { M } & 3: 02 & 0 & 1 & 0 & 1 & 2\end{array}$

$\begin{array}{lllllll}\text { M } & 7: 02 & 0 & 0 & 0 & 0 & 0\end{array}$

$\begin{array}{lllllll}\mathrm{F} & 2: 02 & 1 & 1 & 1 & 1 & 4\end{array}$

$\begin{array}{lllllll}\mathrm{F} & 4: 02 & 0 & 1 & 0 & 1 & 2\end{array}$

F $9: 03 \quad 00011$

\section{Schipperke}

$\begin{array}{lllllll}\text { F } & 9: 06 & 1 & 0 & 1 & 0 & 2\end{array}$

382 Shiba

$\begin{array}{lllllll}\text { M } & 5: 03 & 1 & 0 & 1 & 0 & 2\end{array}$

383 Toy Poodle

$\begin{array}{lllllll}\text { M } & 4: 11 & 0 & 0 & 0 & 0 & 0\end{array}$

$\begin{array}{lllllll}\text { M } & 5: 02 & 0 & 0 & 0 & 0 & 0\end{array}$

384

385

386

387

Average/total/median

$\begin{array}{llllll}5.67 & 7 & 9 & 7 & 10 & 2\end{array}$

M: male; F: female. 
390 Table A2: The number of dogs choosing the actor rather than the neutral person in 391 different numbers of trials (maximum: 4) in each condition

392

393

Condition/no. of choice

0

$1 \quad 2$

\section{4}

395

396

Control condition

Helper condition

$\begin{array}{rrrrrrr}3 & 1 & 11 & 2 & 1 & 2 & 2 \\ 0 & 4 & 7 & 4 & 3 & 2 & 2 \\ 2 & 9 & 6 & 0 & 1 & 1 & 1\end{array}$

397

Nonhelper condition

398 
401 Figure 1. A schematic of the experimental procedure. (a) The owner tries to open a container to get a junk object that is inside. (b) In Helper and Nonhelper conditions, the owner requests help from the actor. (c) In the Helper condition (top row), the actor helps the owner, and (d) the owner successfully opens the container and shows the object to the dog. (e) In the Nonhelper condition (middle row), the actor turns away to show unwillingness to help, and (f) the owner continues trying to open the container, in vain. (g) In the Control condition (bottom row), the owner stops trying for a few seconds. (h) The actor turns away. (i) The owner resumes trying to open the container, in vain. (j) In all conditions, the dog finally chooses to take food from the actor or the neutral person.

411 Figure 2. A box plot of the number of choices for the actor instead of the neutral person

412 in each condition. The plot shows medians, first and third percentiles, ranges and outliers 413 in dots. 